\title{
Processing Of Marine Products: Sustainability, Competitiveness And Financial Viability Of The Canned Food Industry In Spain
}

Lucy Amigo-Dobaño, Universidad de Vigo, Spain $M^{a}$ Dolores Garza-Gil, Universidad de Vigo, Spain Manuel Varela-Lafuente, Universidad de Vigo, Spain

\begin{abstract}
For many decades Spain has been an important fish producer, the fact of which has created an important fish product processing sector. The main sub-sector is the canned food industry; in fact, Spain is the main canned fish and seafood producer in the EU. This paper studies the economic and financial structure of the canned food industry in Galicia, a region where the majority of the sector is located. The study is presented from the point of view of a prospective increase in demand and the risks associated with greater international competition, which obliges companies in the sector to apply more competitive strategies in order to guarantee the activity's future, both from the perspectives of access to consumers as well as business organisation and scale. The result will impact on the regional economy and on the way in which fishing resources are dealt with.
\end{abstract}

Keywords: Fishing resources, canned food industry, economic analysis.

\section{INTRODUCTION}

pain has played a significant role in world fishing production. It is perhaps less well known that this has given rise to the development of an important fish product processing sector made up of several different sub-sectors, the most representative of which are the smoked fish sub-sector, the finished product subsector and the canned food companies, the most important sub-sector. Our analysis focuses on this sub-sector, more specifically on the Autonomous Community of Galicia (north-west of Spain), where the majority of production takes place and where the activity of the fishing sector as a whole implies around $3 \%$ of the regional gross product.

According to FAO data, $50 \%$ of the world's canned fish and seafood production is concentrated in five countries. Thailand tops the list with $23 \%$ of production, followed by Spain with $10.1 \%$ of world production. In Europe, Spain is at the top of the list, concentrating approximately 50\% of EU-15 production in 2005. Specifically, the volume of production of Spanish canned food companies has increased by approximately $42 \%$ in the last ten years and, in particular, $4.7 \%$ with respect to the previous year, reaching a total of 325,000 tonnes in 2006 .

The canned food industry in Galicia is one of the basic components within the sector as a whole in Spain, with production reaching approximately 267,000 tonnes, which represents $80 \%$ of the national total. 64 canned food companies exist in Galicia at present; 147 operational on a national level, employing 6,912 workers, 15,500 workers on a national level. ${ }^{1}$ The Galician canned food industry is principally made up of family businesses with a scant amount of outside capital. The present situation is the culmination of a long historical process of business concentration based on a fragmented, traditionally-structured, family business sector. 
From this perspective and, considering a prospective demand increase scenario which includes the risks involved in international competition, especially from Asia and Latin America, the aim of this study is, firstly, to analyse the sector's economic and financial structure. In particular, we aim to obtain indicators which enable us to evaluate the present financial situation of the canned food industry in Galicia and, in this way, to document an eventual strategic plan for the sector in the future which, along with the rest of the sea-industry composite, constitutes a fundamental axis in Galicia's economy. In this context, most literature focuses on analysing the extractive sector and its implications on the state of the resources and economic development, from different standpoints and perspectives. However, few studies aimed at analysing the situation of the canned food sector, and specifically its financial viability and implications in terms of sustainable development, exist Anfaco (2002) and Schmidt. (2007).. The study we present takes on extra importance on the basis of this scenario.

In order to achieve our aims, the study is structured in the following way. Firstly, the data used is presented and some of its basic features in the sample considered are pointed out. In the next section, the economic results of the Galician canned food companies are presented, considering profitability and solvency in detail, following a financial ratio analysis method, and the net worth-finance equilibrium of the sector. Finally, we set out the main conclusions and make some reflections in terms of sustainable development, thus contributing to recommendations for the creation of possible future strategies which optimally guarantee the sector as a supplier for human consumption and at the same time the sustainability of the sector.

\section{DESCRIPTION OF STUDY CASE}

The data base used in the study is made up of the financial data of the 64 companies of which the Galician canned food sector is comprised. These companies are divided up into 8 zones - Vigo Zone, Morrazo Zone, Salnés Region, Pontevedra Zone, the Barbanza Peninsula, Costa da Morte, North Coruña Zone and Lugo Zone- which employ a total of 6,912 persons. Specifically, we are in possession of the series of data relating to the year 2005. The data was obtained from Informa D\&B, S.A.

The end aim of the study being to illustrate the financial situation of Galicia's canned food companies, we will now present an analysis focussing fundamentally on the study of Finance-Net Worth Structure Ratios of the sector. Table 1, with the aim of characterising the sector, shows the representativity of each of the zones in generating turnover income. 2 In general terms, we can appreciate an important concentration of the Galician canned food sector in the Barbanza Peninsula -followed by the important zones of Vigo and the north of Coruña- with a total turnover volume from the Barbanza zone of approximately six hundred million euros in 2005, which represents almost fifty percent of the total amount generated by Galicia.

Table 1. Turnover Volumes and Concentration. Year 2005.

\begin{tabular}{|l|c|c|}
\hline \multicolumn{1}{|c|}{ Zone } & $\begin{array}{c}\text { Turnover 2005 } \\
\text { (Euros) }\end{array}$ & $\begin{array}{c}\text { Percentage } \\
(\boldsymbol{\%})\end{array}$ \\
\hline Vigo Zone & $251,170,463.99$ & 20.84 \\
\hline Morrazo Zone & $51,995,760.67$ & 4.31 \\
\hline Salnés Region & $83,231,335.84$ & 6.90 \\
\hline Pontevedra Zone & $37,230,062.25$ & 3.08 \\
\hline Barbanza Peninsula & $586,451,497.68$ & 48.68 \\
\hline Costa Da Morte & $45,364,723.88$ & 3.76 \\
\hline North Coruña Zone & $148,061,639.42$ & 12.28 \\
\hline Lugo Zone & $1,460,000.00$ & 0.12 \\
\hline Total Turnover & $1,204,965,483.73$ & 100 \\
\hline
\end{tabular}

Source. Own compilation from D\&P.

Companies in general, including canned food companies, are more than ever facing the challenge of assimilating considerable and continuous changes, not only environmental but also social, technological, regulatory 
and legislative changes, among others, as well. This makes it necessary to speed up the decision-making process in the business and institutional fields so as to be able to adapt this changing and complex world. This process makes it essential to develop all a company's potential, meaning it is also necessary to have an in-depth knowledge of its economic structure, in order to ensuring that not only high profitability rates are obtained but also from the perspective of sustainable medium and long-term economic growth.

Another of the unique features of the sector is that it is forced to work with a reduced number of species: five of such species (tuna, sardine, mussel, mackerel and anchovy) represent $85.6 \%$ of the total processed by the industry in 2005, and all have seen their volume of production increase in the last financial year registered. And in general it is necessary to point out that an increase of $42 \%$ of the total produced by the sector has occurred in the last ten years.

\section{PROFITABILITY AND SOLVENCY. ECONOMIC RESULTS OF THE CANNED FOOD COMPANIES}

Once the scenario which is the subject of our analysis has been presented, we will focus our attention on analysing in detail the solvency of the Galician canned food companies in the year 2005. In order to do so, we will structure the study according to the size of the companies, taking their rate of turnover as an instrumental variable, enabling us to obtain results which make it possible to pose some interesting reflections on the net worth situation of the Galician canned food companies and its relationship with their level of financial stabilisation.

Initially, in Table 2 the Galician canned food companies are presented, structuring the information according to their size or scale, represented in this study by their rate of turnover. It can be observed that we have divided them up in terms of six possible levels, the first of which correspond to the companies with a lower turnover rate and the last to those with the highest rates.

In said table an important level of sector concentration can clearly be seen, given that approximately $18.75 \%$ of Galician companies -large companies- generate $82.65 \%$ of their turnover and $71 \%$ of profit during the year analysed. For their part, the smaller companies have a much lesser impact on generation of value -around $0.04 \%$-, generating $2.75 \%$ of profit. Among these two groups we can distinguish an important volume of companies which could be classified as medium-sized, around $50 \%$ of the companies, which generate $17.32 \%$ of the total turnover and $24.86 \%$ of the total profit.

Table 2. Economic Results of the Canned Food Companies.

\begin{tabular}{|c|c|c|c|}
\hline Companies -Rate of Turnover- & $\begin{array}{c}\text { Companies } \\
(\%)\end{array}$ & $\begin{array}{c}\text { Percentage of Turnover } \\
(\%)\end{array}$ & $\begin{array}{c}\text { Percentage of Profit } \\
(\%)\end{array}$ \\
\hline$\leq 600,000$ euros & 10.94 & 0.01 & 0.26 \\
\hline 600,000 euros $-2,000,000$ euros & 15.63 & 0.03 & 2.49 \\
\hline $2,000,000$ euros $-3,000,000$ euros & 18.75 & 0.74 & 2.93 \\
\hline $3,000,000$ euros $-\quad 6,000,000$ euros & 17.19 & 2.25 & 12.46 \\
\hline $6,000,000$ euros $-30,000,000$ euros & 18.75 & 14.32 & 11.47 \\
\hline More than $30,000,000$ euros - & 18.75 & 82.65 & 71.00 \\
\hline
\end{tabular}

Source. Own compilation from D\&P.

Table 3 below aims to complement the information on the situation of the canned food companies, presenting data relating to the generation of employment according to their level of turnover, from which we can also obtain an idea as to sector concentration. 
Table 3. Size and Employment Level of the Canned Food Companies.

\begin{tabular}{|c|c|c|}
\hline Companies -Rate of Turnover- & $\begin{array}{c}\text { Employment } \\
\text {-Average rate- }\end{array}$ & $\begin{array}{c}\text { Concentration of Employment } \\
(\%)\end{array}$ \\
\hline$\leq 600,000$ euros & 12 & 1.21 \\
\hline 600,000 euros $-2,000,000$ euros & 27 & 3.56 \\
\hline $2,000,000$ euros $-3,000,000$ euros & 34 & 5.96 \\
\hline $3,000,000$ euros $-6,000,000$ euros & 45 & 7.17 \\
\hline $6,000,000$ euros $-30,000,000$ euros & 115 & 20.04 \\
\hline $30,000,000$ euros $-196,298,252$ euros & 357 & 62.06 \\
\hline
\end{tabular}

Source. Own compilation from D\&P.

We could identify the companies' solvency with the guarantee they offer their creditors that debts will be paid off and, in this sense, given by the direct relationship between the Company's Real Assets and its Total Debt. Table 4 sums up the most relative results obtained from the analysis.

The evolution marked by the data provided is that of the high level of variability of solvency among the different canned food companies in accordance with their size. Specifically, the percentage of assets financed by outside resources is extremely high for the smaller companies, with figures reaching levels of $99 \%$ for companies with an annual turnover of less than six hundred thousand euros. For their part, the level of asset borrowing of the medium-sized companies stands at around 65\%, which is high but can be sustained. Finally, it can be seen that the large companies are those most financially stable, with levels of borrowing standing at around 574\%, at a safe distance from the maximum level of sustainable borrowing.

Table 4. Net Worth Position and level of Solvency of the Canned Food Companies

\begin{tabular}{|c|c|}
\hline \multicolumn{1}{|c|}{ Companies -Rate of Turnover- } & $\begin{array}{c}\text { Level of Borrowing } \\
(\%)\end{array}$ \\
\hline$\leq 600,000$ euros & 99.14 \\
\hline 600,000 euros $-2,000,000$ euros & 51.40 \\
\hline $2,000,000$ euros $-3,000,000$ euros & 69.31 \\
\hline $3,000,000$ euros $-6,000,000$ euros & 61.56 \\
\hline $6,000,000$ euros $-30,000,000$ euros & 57.79 \\
\hline More than 30,000,000 euros - & 56.71 \\
\hline
\end{tabular}

Source. Own compilation from D\&P.

In this sense, the values reached to describe the financial situation of the Galician canned food companies mark a behavioural trend which backs up the idea that their stability relates to their size or scale, measured via their rate of turnover. It is particularly significant to point out that the most critical levels with regard to financial stabilisation is shown by the smaller companies, high but sustainable for the medium-sized companies. For their part, the larger companies are those whose assets are for the most part covered by their own resources, and are therefore those which are most financially stable.

Table 5 below shows the results of some of the most significant ratios normally used, which aim to sum up the economic-financial situation of the companies comprising the canned food sector in Galicia. In order to do so, different net worth aspects relating to the balance sheet, as well as the results deriving from the profit and loss statement and, finally, solvency via the companies' cash flow analysis are contemplated. Specifically, we present the results of the list of assets financed by outside resources and their relationship with the equity and the floating capital.

We can see that the values obtained show a profitability for the canned food sector which can be described as average, tending towards insufficient. For their part, the cash flow ratios are slightly higher, with figures that 
enable us to describe it as good. Insofar as the situation resulting from the companies' net worth balance analysis is concerned, the situation is much poorer and the levels of borrowing moderate.

Table 5. Canned Food Companies' Financial Situation Ratios.

\begin{tabular}{|l|c|}
\hline \multicolumn{1}{|c|}{ Ratios- } & Average Values \\
\hline Profitability & $4-5 / 9$ \\
\hline Cash flow & $6-7 / 9$ \\
\hline Balance & $5-6 / 9$ \\
\hline Borrowing & $6 / 9$ \\
\hline
\end{tabular}

Source. Own compilation from D\&P.

Below, and with the aim of attempting to lend the results set out above greater strength and depth, we deal with the analysis considering their connection with the size of the companies. Table 6 reflects the results of the different ratios per segment turnover.

Table 6. Economic-Financial Results and Size of Company.

\begin{tabular}{|l|c|c|c|c|c|}
\hline \multicolumn{1}{|c|}{ Companies-Rate of Turnover } & $\begin{array}{c}\text { Companies } \\
(\boldsymbol{\%})\end{array}$ & Profitability & Cash flow & Balance & Borrowing \\
\hline$\leq 2,200,000$ euros & 25 & 4.9 & 5.2 & 5 & 5.5 \\
\hline $2,200,000$ euros - 5,000,000 euros & 25 & 4.5 & 6.3 & 3.8 & 5.6 \\
\hline $5,000,000$ euros - 20,000,000 euros & 25 & 4.9 & 7.8 & 6.7 & 6.5 \\
\hline $20,000,000$ euros - 200,000,000 euros & 25 & 4.7 & 7.15 & 6 & 6.3 \\
\hline
\end{tabular}

Source. Own compilation from D\&P.

The analysis of the data provided shows the importance the size of the company has on their economic and financial results. To this end, we would point out firstly that, although the profitability ratios do not reflect considerable differences between the companies in terms of their size, there are indeed significant differences in cash flow levels. Along this line, we can observe a direct and positive relation between the size of the companies and greater cash flow, which could be described as average for the smaller companies and good or very good for the bigger ones. Along the same line, it can also be corroborated that a close link between levels of borrowing and company size exists, the companies with higher turnover rates reflecting less weak borrowing levels, whereas the small and medium-sized companies have average borrowing levels. In consequence, it is worth emphasising the results shown by the net worth equilibrium ratios, from which we can observe a favourable equilibrium situation for the larger companies and a weaker one for the small and medium-sized companies.

\section{FINAL CONSIDERATIONS AND IMPLICATIONS FOR SUSTAINABLE DEVELOPMENT}

The accounting information of the sixty-four canned food companies in Galicia points to a situation in which, in general terms, they fall within the profit zone. It is appropriate to point out, for the more stabilised companies - which are also the larger ones- greater expectations for the future can be perceived, as their ratios indicate that, incurring a minimum risk, they can increase their structural loads, which will allow them to considerably increase their production capacity, increasing their capacity to obtain profits. For their part, the medium-sized companies, and more especially the small-sized companies, ought to consider the need to implement measures which allow them to improve their financial situation in the search to achieve the basic principles of accounting equilibrium, with the aim of becoming economically viable in the medium and long terms.

The empirical analysis stresses the need for a plan for an economic boost, and, in parallel, for adaptation to the principles of sustainable development, insofar as the medium-sized companies and especially the small-sized companies are concerned. Along with these measures, the Galician and Spanish canned food sector as a whole, and 
given the internalisation process in which it finds itself immersed, must focus its attention basically on the search for added value. The increase in product quality, the search for possible future market footholds, increases in $R+D$ investment, innovative marketing proposals and improvements in logistical efficiency or the possibility of setting up strategic alliances, among others, is fundamental.

The conjunction of endogenous and exogenous data seems to recently be provoking some answers from sector companies. These strategies point in two directions. On the one hand, the opening of production diversification lines which, in turn, open up other directions: the adapting of the product to consumer needs and ranges of preference (new prepared foods, new recipes); the incorporation of health and ecology factors to the products (low salt content, omega 3, ecolabelling, etc.) and, of course, new species, including marine algae. On the other hand, the strategies point to internationalisation, no only increasing product exports and supply imports but, above all, opening the possibility of new factories in third countries (new markets, proximity to raw materials).

If, as it would seem, the canned food sector maintains an important level of activity and is adopting new strategies, responsible behavioural codes with regard to the use of the resources must also apply, insofar as to be included in the fishing-industry composite and that their actions affect the demand for fish products. Having said this, in the new strategic tendencies, evidence of internalisation in sector production decisions with regard to sustainability principles can also be detected, to the extent that companies can benefit from market response, on account of consumer sensitivity, as well as from lines of public aid in this direction

We have pointed out some of the trends observed at present with regard to business strategy and, although there is concern over the effects of a growing demand for some species in particular, some of these trends would seem to be particularly compatible with sustainable development. However, only a short time has passed with these experiences, and therefore the evaluation of results is not yet possible.

Finally, all of these contributions can be of special spatial and sectorial interest, on account of the importance of the contribution of the canned food industry to the strengthening of the sea-industry composite and to the social and economic development of the areas which depend on the sea and its resources.

$\mathbf{M}^{\mathbf{a}}$ Dolores Garza-Gil was born in Vigo (Spain) in 1966 and received her BA degree from University of Santiago de Compostela in 1990. She is PhD in Economics since 1995 and Associate Professor in Department of Applied Economics in University of Vigo since 1998. She is an expert in fisheries economics focusing on bioeconomics modelling, economic evaluation and fisheries management and regulation. She has participated in several international projects and her research has been published in different journals: among others, Marine Policy, Ecological Economics, Environmental and Resources Economics, Disasters, American Journal of Agricultural Economics, Ocean and Coastal Management.

Manuel Varela-Lafuente is Ph.D in Economics since 1982 and Professor in Department of Applied Economics in University of Vigo, Spain, since 1992. He is an expert in natural resource economics, especially in fisheries economics focusing on economic evaluation and fisheries management and regulation. He has participated in several international projects and his research has been published in different journals: among others, Marine Policy, Fisheries Research, The Journal of Disasters Studies, Policy and Management, American Journal of Agricultural Economics, Ocean and Coastal Management.

Lucy Amigo Dobaño was born in Caracas (Venezuela) in 1968 and received her BA degree from University of Vigo in 1991. She is PhD in Economics since 2001 and Associate Professor in Department of Applied Economics in University of Vigo since 2002. She is an expert in financial markets and in fisheries economics focusing on econometric modelling, economic analysis fisheries management and regulation. She has participated in several international projects and her research has been published in different national and international journals: among others, Journal of Applied Business Research, International Business \& Economics Research Journal, Review of Financial Markets, Revista Española de Financiación y Contabilidad and Marine Policy. 


\section{RERERENCES}

1. Catarci, C. (2004): "The World Tuna Industry. An Analysis of Imports and Prices, and of Their Combined Impact on Catches and Tuna Fishing Capacity". Roma: FAO, Fisheries Department.

2. Fama, E.; French, K. (2002): "TestingTrade-Off and Peeking Order Predictions about Dividends and Debt", The Review of Financial Studies, $\mathrm{N}^{\circ}$ 15, 1, págs.1-33.

3. FAO (2004): Situación y acontecimientos recientes importantes relacionados con el comercio internacional de productos pesqueros. Bremen: Comité de Pesca, Subcomité sobre Comercio Pesquero.

4. Franquesa, Ramón (2001): "El comercio pesquero y la WTO (Organización Mundial de Comercio)". VI Sesion del Foro Cientifico de la Pesca Española en el Mediterraneo. 2001

5. $\quad$ Franquesa, Ramón: (2004): "Some experience from the Spanish fishing sector: Non tariff measures and solutions"-Case Study for the Fisheries Market Liberalisation Project, OECD Fishing Committee, AGR/FI(2001)10/PART2, 2004

6. Griannetti, M. (2003): "Deo Better Institutions Mitigate Agency Problems? Evidence from Corporate Finance Choices", Journal of Finance and Quantitative Analysis, $\mathrm{N}^{\circ} 38$, 1,págs. 185-211.

7. Harris, M; Raviv, A.(1991): “The Theory of Capital Structure”, Journal of Finance, no 46, 1, págs. 297 355.

8. INFOPESCA - FAO (2005): "Presente y futuro de los mercados de pescado y productos pesqueros de la pesca a pequeña escala” Enfocado especialmente en los casos de: México, Perú y Brasil

9. Josupeit, H. (2004): La producción y el mercado de las conservas y semiconservas de pescados y mariscos. Roma: FAO.

10. Josupeit, H.; Catarci, C. (2004): “The World Tuna Industry-an Análisis of Imports, Prices, ando f Their Combined Impact on Tuna Catches and Fishing Capacity", FAO.

11. Josupeit, H.; Franz, N. (2003): "Demand and Fish Trade", FAO.

12. Landa, F. J. and Velasco, F. (2004), "Análisis dinámico del mercado actual y potencial de las organizaciones", Revista Europea de Dirección y Economía de la Empresa, ISSN 1019-6838, Vol. 13, No 1, págs. 131-140.

13. Leiva Moreno, I.; Majkowski, J. (2004): "Status of tuna Stocks", 17th Meeting of the Standing Comité on Tuna and Billfish. Majura (Marshall Islands).

14. Miyake, P.M. (2003): "Brief Review of World Tuna Fisheries", (Fisheries Technical Paper).

15. Muñoz Guarasa, M. (2002): "Deslocalización sectorial de la inversión directa extranjera en España", Boletín Económico del ICE, núm. 2744.

16. Muran, M. and Petra, M. (2004):" Russian Federation Fishery Products Annual 2004”, GAIN Report (Global Agriculture Information Network).

17. Núñez, R. (2006): “Las empresas conserveras y el mercado mundial del atún”, Revista Galega de Economía, ISSN 1132-2799, Vol. 15, No 1, págs. 1-20.

18. Ruesga, S.M.; Da Siva, J. (2004): "Direct Spanish Foreign Investment in Latin America: Determinants and Company Strategy", Canadian Journal of Development Studies, vol. XXV, núm. 2, pp. 321-335.

19. Schmidt, C. (2004): Globalisation, Industry Structure, Market Power and Impact on the Fish Trade Opportunities and Challenges for Development (OECD) Countries. París: OECD.

\section{FOOTNOTES}

\footnotetext{
${ }^{1}$ Among all of the canned products the sector produces, tuna is the most important, with a production of over 190,000 tonnes at a value of 470 million euros, followed by sardines and mackerel, whose volume of production has also increased, whereas the production of others, such as octopus, squid, cockles, razor clams and clams, has decreased. Asociación Nacional de Fabricantes de Conservas de Pescados y Mariscos- (National Association of Fish and Seafood Canners)- Anfaco.

${ }^{2} \mathrm{~A}$ retrospective analysis shows that the trend in turnover has been both positive and significant in recent years.
} 
NOTES 